\title{
EFEKTIVITAS BIMBINGAN UJIAN KOMPETENSI DENGAN METODE SMALL GROUP DISCUSSION (SGD) ONLINE DAN OFFLINE TERHADAP HASIL NILAI TRY OUT UJIAN KOMPETENSI DI PRODI D-IV KEBIDANAN POLTEKKES KEMENKES JAYAPURA
}

\author{
Sri Wahyuni ${ }^{1}$, Syahriyanti ${ }^{2}$ \\ ${ }^{1,2}$ Prodi D-IV Kebidanan Jurusan Kebidanan Poltekkes Kemenkes Jayapura \\ Email : sriwahyunijayus@gmail.com
}

\begin{abstract}
ABSTRAK
Pendahluan. Tren kelulusan first taker ujian kompetensi bidan di Prodi D4 Kebidanan Jayapura mengalami penurunan pada tahun 2018 menjadi 42\% yang sebelumnya 82\% pada tahun 2017 sehingga prodi mengambil langkah untuk melakukan bimbingan ujian kompetensi dengan menggunakan metode small group discussion. Tujuan. Penelitian ini bertujuan untuk mengetahui efektifitas bimbingan ujian kompetensi dengan metode small group discussion online dan offline terhadap kenaikan nilai try out ujian kompetensi. Metode. Metode yang digunakan yaitu penelitian eksperimen semu (Quasy Experiment) dengan rancangan pretestposttest with control group design. Penelitian ini menggunakan 2 kelompok yaitu kelompok kontrol (offline) dan kelompok eksperimen (online) yang dipilih secara kuota sampling dengan jumlah sampel tiap kelompok masing masing 30 orang. Hasil. Uji statistik yang digunakan pada kelompok berpasangan dengan data berdistribusi normal menggunakan uji Paired Sample Test dan pada data yang berdistribusi tidak normal menggunakan uji Wilcoxon, pada kelompok tidak berpasangan dengan data berdistribusi tidak normal menggunakan uji Mann Whitney. Hasil analisis untuk efektivitas menggunakan bimbingan dengan metode small group discussion online dan offline ternyata tidak ada perbedaan dengan nilai $p$ value $(0.728)>\alpha(0,05)$, artinya jika dilakukan secara online maupun offline metode small group discussion sama-sama efektif terhadap hasil nilai try out ujian kompetensi.
\end{abstract}

Kata Kunci: Keefektifan; Small Group Discussion; Ujian Kompetensi

\section{ABSTRACT}

Introduction. The trend of passing the first taker for the midwife competency exam in the D4 Midwifery Study Program in Jayapura decreased in 2018 to 42\% from 82\% in 2017 and study programs took steps to conduct competency examination guidance using the small group discussion. Purpose. This study aims to determine the effectiveness of competency exam guidance with the online and offline small group discussion method on the increase in the score of competency test try outs. Methods. The method used is quasi-experimental research (Quasy Experiment) with a pretest-posttest design with a control group design. This study used 2 groups, namely the Control Group (Offline) and the Experiment Group (Online) which were selected by means of quota sampling and group each consisted of 30 people. Result. The statistical test used in paired groups with normally distributed data used the Paired Sample Test and for data that were abnormally distributed using the Wilcoxon test, for unpaired groups with 
abnormally distributed data used the Mann Whitney test. The results of the analysis for the effectiveness of using guidance with the online and offline small group discussion method, it turns out that there is no difference with the value of $P$ value (0.728)> $\alpha(0.05)$, meaning that if done online or offline the small group discussion method is equally effective in increasing the value. competency exam tryout.

Key Words: Competency Test; Effectiveness; Small Group Discussion

\section{PENDAHULUAN}

Persentase kelulusan uji kompetensi nasional bidang kesehatan masih rendah. Pada D-3 Kebidanan ada 122.844 siswa dari 554 institusi hanya 71.78\% yang lulus sehingga menjadi keprihatin Kemenristekdikti karena lulusan tenaga Kesehatan yang tidak lulus tidak akan mendapatkan Surat Tanda Registrasi (STR) (Zubaidah, 2016).

Kelulusan first taker ujian kompetensi bidan D4 Kebidanan Jayapura periode pertama pada tahun 2017 adalah 82\%, periode kedua pada tahun 2018 mengalami penurunan menjadi 42\%, akan tetapi pada tahun 2019 kelulusan ujian kompetensi mengalami kenaikan yang sangat pesat menjadi 100\% karena sudah dilakukan bimbingan Ujian Kompetensi Bidan dengan Metode Small Group Discussion (D4 Kebidanan Jayapura, 2019).

Menurut pendapat Arends (2015) menyatakan bahwa "the true learning is when students take responsibility for their own learning and not depend solely on a teacher". Makna dari penjelasan di atas adalah pembelajaran yang tepat adalah dimana seorang siswa memiliki tanggung jawab sendiri atas apa yang mereka pelajari dan tidak bergantung terus menerus kepada guru. Berdasarkan pernyataan di atas dapat dikatakan bimbingan Ujian kompetensi akan bermakna apabila pembelajaran terpusat pada mahasiswi. Pembelajaran yang terpusat pada mahasiswi akan meningkatkan rasa ingin tahu terhadap materi yang sedang dipelajari. Munculnya rasa ingin tahu akan mempengaruhi kemandirian mahasiswi untuk mencari tahu apa yang ingin diketahuinya.

Menurut Tabrizi, A., Pourfeizi, H.H., Aslani, H. (2016) "the small group discussion method is an effective method in residency training that enhances their learning ability compared to traditional methods of education”. Makna dari pendapat di atas adalah Metode Pembelajaran Small Group Discussion merupakan metode efektif yang dapat diterapkan di suatu tempat pelatihan untuk meningkatkan kemampuan belajar mereka dibandingkan dengan metode belajar tradisional. 
Menurut Abdul Majid (2013) Metode Pembelajaran Small Group Discussion dilakukan dengan cara membagi siswa menjadi beberapa kelompok. Setiap kelompok terdiri dari 3-5 orang siswa. Langkah awal yang dilakukan adalah guru menyajikan masalah secara umum kemudian masalah umum tersebut dibagi-bagi menjadi sub-sub masalah yang akan dipecahkan oleh siswa. Setelah selesai siswa mempresentasikan hasil diskusinya di depan kelas.

Menurut Kosasih (2015) pembelajaran berbasis kelompok memiliki tujuan yaitu meningkatkan partisipasi optimal siswa dalam belajar, memberi pembelajaran mengenai kepemimpinan dan pengalaman mengambil keputusan kelompok dan memberi kesempatan untuk berinteraksi dan belajar dengan siswa lain dengan latar belakang yang berbeda.

Menurut Jumanta Hamdayana (2016) Metode Pembelajaran Small Group Discussion akan memberikan hasil yang maksimal apabila dipersiapkan secara serius, dan memenuhi kriteria pelaksanaan Metode Pembelajaran Small Group Discussion.

Menurut Kosasih (2015) kelebihan dari Metode Pembelajaran Small Group Discussion adalah Hasil keputusan lebih lengkap karena didasarkan pada keputusan bersama. Anggota kelompok dapat dimotivasi oleh kehadiran anggota kelompok lain. Anggota kelompok yang pemalu lebih berani untuk mengungkapkan pendapat pada diskusi kelompok kecil dibandingkan pada diskusi umum., Anggota kelompok lebih merasa terikat dalam melaksanakan keputusan kelompok, karena mereka terlibat di dalam proses pengambilan keputusan, Diskusi kelompok dapat meningkatkan pemahaman diri sendiri dan orang lain.

Meskipun demikian, menurut Jumanta Hamdayana (2016) Metode Pembelajaran Small Group Discussion memiliki kekurangan, antara lain Waktu belajar lebih Panjang, Dapat terjadi pemborosan waktu., Anak yang pemalu dan pendiam menjadi kurang agresif, Dominasi siswa tertentu dalam diskusi.

Berdasarkan uraian di atas, menunjukkan bahwa Metode Pembelajaran Small Group Discussion memiliki kelebihan dan kekurangan. Guru harus mampu memaksimalkan kelebihan Metode Pembelajaran Small Group Discussion sehingga kekurangan Metode Pembelajaran Small Group Discussion dapat disikapi dengan baik. Kelebihan Metode Pembelajaran Small Group Discussion antara lain informasi yang diperoleh lengkap, siswa lebih leluasa untuk mengungkapkan pendapatnya, memiliki ikatan dalam membuat keputusan di dalam kelompok. Kekurangan Metode Pembelajaran Small Group Discussion yaitu memerlukan waktu yang lama, adanya dominasi siswa tertentu, dan adanya topik di luar pembahasan diskusi. 


\section{TUJUAN}

Tujuan penelitian ini yaitu untuk mengetahui efektivitas bimbingan ujian kompetensi dengan metode Small Group Discussion (SGD) online dan Offline terhadap hasil nilai try out ujian kompetensi di prodi D-IV kebidanan poltekkes kemenkes Jayapura.

\section{METODE}

Jenis penelitian ini merupakan eksperimen semu (Quasy Experiment) dengan rancangan pretest-posttest with control group design yang mana dibagi menjadi 2 kelompok yaitu Kelompok Kontrol (Offline) dilakukan bimbingan belajar dengan SGD dengan pertemuan tatap muka konvensional di kelas sebanyak 7 kali selama 7 hari dan mendapatkan materi yang berbeda-beda setiap harinya mulai dari kehamilan, persalinan, nifas, neonatus, kespro, KB dan komunitas. Pada kelompok eksperimen (Online) dilakukan bimbingan belajar SGD dengan menggunakan aplikasi zoom meeting atau google meet dan dilakukan pretest-posttest menggunakan socorative student dengan 7 kali pertemuan selama 7 hari dan disetiap pertemuannya mendapatkan materi yang berbeda-beda mulai dari kehamilan, persalinan, nifas, neonatus, kespro, KB dan komunitas. Teknik sampling yang digunakan kuota sampling dengan pengambilan sampel sebesar 60 orang yang dibagi menjadi 2 kelompok yaitu 30 orang pada Kelompok Kontrol (Offline) dan 30 orang pada Kelompok Eksperimen (Online) dimana pada setiap kelompok kontrol maupun kelompok eksperimen dibagi menjadi 7 stase (kehamilan, persalinan, nifas, neonatus, kespro, KB dan komunitas) dan di setiap stase terdiri dari 4-5 orang.

Uji statistik yang digunakan pada kelompok berpasangan dengan data berdistribusi normal menggunakan uji Paired Sample Test dan pada data yang berdistribusi tidak normal menggunakan uji Wilcoxon, pada kelompok tidak berpasangan dengan data berdistribusi tidak normal menggunakan uji Mann Whitney. Teknik pengumpulan data dilakukan dengan data primer yaitu mengambil nilai ujian try Out sebelum dan sesudah dilakukan bimbingan SGD baik bimbingan SGD secara offline di kelas maupun bimbingan SGD secara online menggunakan aplikasi googlemeet maupun zoommeeting. 


\section{HASIL}

Tabel 1. Perbedaan hasil Ujian Try Out antara pre test dan post test pada kelompok kontrol (Bimbingan SGD Offline)

\begin{tabular}{lccccc}
\hline & Mean & SD & SE & $P_{\text {value }}$ & $\mathrm{n}$ \\
\hline PreTest Kelompok Kontrol (Offline) & 53.7617 & 11.83916 & 2.16152 & & \\
PostTest Kelompok Kontrol (Offline) & 61.2540 & 10.64842 & 1.94 & 0.000 & 30 \\
\end{tabular}

Berdasarkan tabel 1. di atas sebelum dilakukan small group discussion pada Kelompok Kontrol (Offline) diperoleh nilai mean sebesar 53.7617 dan setelah dilakukan small group discussion diperoleh nilai mean sebesar 61.2540. Hasil uji menggunakan uji Paired Sample Test karena data berdistribusi normal sehingga diperoleh nilai $P$ value $(0.000)<\alpha(0,05)$, dapat diartikan bahwa ada perbedaan hasil belajar mahasiswi sebelum dan sesudah dilakukan bimbingan Ujian kompetensi dengan small group discussion.

Tabel 2. Perbedaan hasil Ujian Try Out antara pre test dan post test pada kelompok kontrol (Bimbingan SGD Online)

\begin{tabular}{|c|c|c|c|}
\hline & & Mean Rank & $P_{\text {value }}$ \\
\hline PostTest Online - PreTest Online & $\begin{array}{c}\text { Negative Ranks } \\
\text { Positif Ranks }\end{array}$ & $\begin{array}{c}2.50 \\
17.00\end{array}$ & 0.000 \\
\hline
\end{tabular}

Berdasarkan tabel 2. di atas yang dilakukan pada Kelompok Eksperimen (Online) didapatkan nilai mean rank negatif sebesar 2.50 dan nilai mean rank positif sebesar 17.00. Hasil uji menggunakan uji Wilcoxon karena data berdistribusi tidak normal sehingga diperoleh nilai Pvalue $(0.000)<\alpha(0,05)$, dapat diartikan bahwa ada perbedaan hasil belajar mahasiswi sebelum dan sesudah dilakukan small group discussion dengan metode Online.

Tabel 3. Selisih Kenaikan nilai Hasil Belajar Mahasiswi Pada Kelompok Kontrol (Offline) dan Kelompok Eksperimen (Online)

\begin{tabular}{ccc}
\hline & Mean Rank & $P_{\text {value }}$ \\
\hline Kelompok Kontrol (Offline) & 31.28 & \multirow{2}{*}{0.728} \\
Kelompok Eksperimen (Online) & 29.72 & \\
\hline
\end{tabular}

Berdasarkan tabel 3. di atas diperoleh nilai mean rank pada Kelompok Kontrol (31.28) dan pada Kelompok Eksperimen (29.72). Hasil uji menggunakan uji Mann Whitney karena data berdistribusi tidak normal sehingga diperoleh nilai $P$ value $(0.728)>\alpha(0,05)$, dapat disimpulkan bahwa tidak ada perbedaan perubahan hasil belajar mahasiswi pada Kelompok Kontrol (Offline) 
dan Kelompok Eksperimen (Online). Artinya, baik bimbingan belajar menggunakan Small Group Discussion baik secara offline maupun Online sama-sama efektif. Namun, Jika dilihat dari perubahan nilai Mean selisih Hasil belajar Offline lebih tinggi yaitu 31,28 jika dibandingkan Selisih menggunakan metode Online nilai Mean nya 29,72.

\section{PEMBAHASAN}

1. Perbedaan Hasil Ujian Try Out Mahasiswi sebelum dan sesudah dilakukan bimbingan Small Group Discussion dengan metode Offline Pada Kelompok Kontrol

Berdasarkan tabel 1. Hasil analisis dengan menggunakan uji Paired Sampel Test diperoleh nilai $P$ value $(0.000)<\alpha(0,05)$, dapat disimpulkan bahwa ada perbedaan nilai hasil belajar antara sebelum dan sesudah bimbingan belajar Small Group Discussion secara offline. Bimbingan yang dilakukan dilakukan secara tatap muka secara langsung tanpa menggunakan koneksi internet. Bimbingan dilakukan selama 7 hari dan didapatkan hasil ada perbedaan hasil nilai ujian tryout sebelumd an sesudah dilakukan bimbingan.

Hal ini sejalan dengan penelitian yang mengatakan bahwa metode belajar dengan Small Group Discussion efektif meningkatkan pengetahuan tentang Kesehatan reproduksi. (Rahmawati and Elsanti 2020). Hasil penelitian lain menunjukkan adanya peningkatan hasil belajar dan keaktifan mahasiswa dengan nilai rata-rata pretest dan posttest pada siklus I yaitu 65,22 dan 70,67 dan pada siklus II, nilai rata-rata posttest yaitu 85,34 setelah dilakukan metode pembelajaran Bahasa Inggris dengan metode SGD(Putriawati, 2019).

Aktivitas belajar pada Bimbingan Ujian Kompetensi bidan merupakan upaya yang dilakukan oleh mahasiswi untuk menggali informasi mengenai teori dan skill dalam kebidanan secara mandiri. Mahasiswi disebut pembelajar aktif apabila ia mampu menemukan informasi atau ilmu baru secara mandiri. Mahasiswi yang mampu memahami teori dan skill dalam kebidanan tidak akan kebingungan jika diberikan soal Ujian Kompetensi yang berbeda karena ia telah mengetahui teknik memecahkan permasalahan yang terdapat dalam soal tersebut sehingga ia dapat menjawabnya dengan percaya diri atau tidak ragu-ragu. Selain dapat menjawab soal dengan benar, mahasiswi tersebut juga mampu memberikan pemahaman kepada teman lainnya yang masih kebingungan. Sehingga dapat terciptanya pembelajaran yang aktif dan kooperatif.

2. Perbedaan Hasil Ujian Try Out Mahasiswi sebelum dan sesudah dilakukan bimbingan Small Group Discussion dengan metode Offline Pada Kelompok Kontrol 
Berdasarkan tabel 2. Hasil analisis dengan menggunakan uji Wilcoxon diperoleh nilai $P$ value $(0.000)<\alpha(0,05)$, dapat diartikan bahwa ada perbedaan hasil belajar mahasiswi sebelum dan sesudah dilakukan small group discussion dengan metode online. Metode yang digunakan secara online menggunakan aplikasi Zoom Meeting atau Google Meet dilakukan dengan jumlah waktu yang sama dengan metode offline yaitu 3 jam per pertemuan.

Hal ini sejalan dengan penelitian yang menyebutkan bahwa pembelajaran online pada pelajaran kimia efektif dalam meningkatkan pengetahuan siswa. (Santoso , 2009). Bimbingan Ujian Kompetensi menggunakan metode Small Group Discussion secara online melatih setiap mahasiswi memiliki potensi yang berbeda-beda. Ketika setiap mahasiswi berdiskusi tentang suatu hal, maka mereka akan meningkatkan kemampuan berpikir dalam memecahkan suatu masalah dalam diskusi tersebut secara mandiri. Untuk mendapatkan jawaban yang pasti dari hasil diskusi mereka disini peran pembimbing sangatlah penting untuk meluruskan kembali jawaban yang kurang tepat sehingga dapat terciptanya pembelajaran yang efektif. Hanya saja proses diskusi ini dilakukan dengan media internet sehingga faktor kestabilan internet sangat penting.

3. Efektifitas Hasil Bimbingan Belajar Mahasiswi Pada Kelompok Kontrol (Small Group Discussion Offline) dan Kelompok Eksperimen (Small Group Disucussion Online)

Berdasarkan tabel 3. Hasil analisis dengan menggunakan uji Mann Whitney diperoleh nilai Pvalue $(0.728)>\alpha(0,05)$, dapat disimpulkan bahwa tidak ada perbedaan perubahan hasil belajar mahasiswi pada Kelompok Kontrol (Offline) dan Kelompok Eksperimen (Online). Artinya, jika dilihat secara statistic keefektifan metode Online dan Offline adalah sama.

Hasil penelitian ini sama-sama efektif dikarenakan jumlah waktu yang digunakan baik media online maupun offline sama-sama menggunakan waktu 3 jam untuk masing-masing pertemuan selama 7 kali pertemuan. Namun, jika dilihat dari nilai Mean pada kelompok offline lebih tinggi yaitu yaitu 31,28 jika dibandingkan Selisih menggunakan metode Online nilai mean nya 29,72. Perbedaan nilai mean tersebut dikarenakan yang menggunakan internet sedikit terganggu jika jaringan sulit, atau baterei lemah saat proses bimbingan dengan metode online ini.

Hal ini tidak sejalan dengan penelitian Santoso (2009) yang menyebutkan bahwa pembelajaran secara online untuk pembelajaran Kimia lebih efektif dibandingkan dengan pembelajaran menggunakan LKS. 


\section{SIMPULAN}

Bimbingan Small Group Discussion baik secara online maupun offline tidak ada beda signifikan dalam meningkatkan hasil nilai Try Out Ujian Kompetensi Kebidanan.

\section{DAFTAR PUSTAKA}

Abdul Majid. 2013. “Strategi Pembelajaran.” In Bandung: Remaja Rosdakarya.

Arends, Richad. 2015. “Learning To Teach.” In New York: McGraw Hill Education.

Burden, P and Byrd, D. 2013. "Methods for Effective Teaching.” In New Jersey: Pearson.

D4 Kebidanan Jayapura. 2019. Data Primer Hasil Ujian Kompetensi Bidan Nasional. Jayapura : Poltekkes Kemenkes Jayapura.

Jumanta Hamdayana. 2016. “Metodologi Pengajaran.” In Jakarta: Bumi Aksara.

Kosasih, E. 2015. "Strategi Belajar Dan Pembelajaran Implementasi Kurikulum 2013." In Bandung: Yrama Widya.

Putriawati, Wiwin. 2019. "Penerapan Metode Pembelajaran Small Group Discussion Untuk Meningkatkan Hasil Belajar Dan Keaktifan Mahasiswa.” Prisma Sains : Jurnal Pengkajian Ilmu dan Pembelajaran Matematika dan IPA IKIP Mataram 7(1): 80-90.

Rahmawati, Kristia, and Devita Elsanti. 2020. “Jurnal Keperawatan Muhammadiyah Efektivitas Metode Ceramah Dan Small Group Discussion Tentang Kesehatan Reproduksi Terhadap Tingkat Pengetahuan Dan Sikap Remaja SMA Muhammadiyah Sokaraja.” (September).

Santoso, Edi. 2009. "Pengaruh Pembelajaran Online Terhadap Prestasi Belajar Kimia Ditinjau Dari Kemampuan Awal Siswa." Tesis Sekolah PascaSarjana Teknologi Pendidikan Universitas Negeri Surakarta: 1-117.

Tabrizi, A., Pourfeizi, H.H., Aslani, H., et al. 2016. "Effect of Small Group Discussion in Residency Education Versus Conventional Education."

Zubaidah, Neneng. 2016. Tingkat Kelulusan Uji Kompetensi Kesehatan Rendah. Okenews.com.dikutip dari https://news.okezone.com/read/2016/04/06/65/1355848/tingkat-kelulusan-uji-kompetensikesehatan-rendah 